\title{
Habitat Use and Activity Patterns of a Terrestrial Turtle (Rhinoclemmys rubida perixantha) in a Seasonally Dry Tropical Forest
}

\author{
Taggert G. Butterfield ${ }^{1}$, Alison Scoville, Andrés García ${ }^{2}$, and Daniel D. Beck \\ Department of Biological Sciences, Central Washington University, Ellensburg, WA 98926, USA
}

\begin{abstract}
We report the results of a field study on Mexican Spotted Wood Turtles (Rhinoclemmys rubida perixantha) in a seasonally dry tropical forest of coastal Jalisco, Mexico. We used field surveys, trail spools, and radio telemetry to investigate activity patterns, estimate home range size with three different techniques, and develop a generalized linear model to identify features associated with habitats used by $R$. $r$. perixantha. We found that turtles were most frequently active at midday, with peak activity occurring from 0900 to $1500 \mathrm{~h}$. During the dry season (January-mid-June), R. r. perixantha showed reduced activity (fewer movements and shorter travel distances) compared to the wet season (late June-September). Home range size did not differ among the three methods we compared, and all estimates revealed that $R$. $r$. perixantha have small home ranges, with males having larger home ranges than females. Sites used by turtles were positively associated with leaf litter and woody debris, herbaceous plants, vegetation, vine-like shrubs, and sloped terrain, and negatively associated with bare ground. Our findings can be used to strengthen future conservation efforts for R. r. perixantha, as well as other terrestrial geoemydids.
\end{abstract}

Key words: Geoemydidae; Home range; Mexican Spotted Wood Turtles; Mexico; Microhabitat; Radiotelemetry

Over half of all turtle species on the International Union of Conservation and Nature (IUCN) red list are considered threatened or endangered (Turtle Taxonomy Working Group 2017), and one in four turtle species belongs to Family Geoemydidae (Order Testudines). Not only are geoemydids the most diverse turtle family (Spinks et al. 2004), but they are also experiencing some of the greatest anthropogenic impacts among turtles from habitat loss, exploitation, and illegal trade (Turtle Conservation Coalition 2011; Gong et al. 2017). Geoemydids in the New World are represented by only nine species in the genus Rhinoclemmys, which includes aquatic, semiaquatic, and terrestrial species (Ernst 1978; Legler and Vogt 2013). Some, such as the semiaquatic Rhinoclemmys areolata (Vogt et al. 2009), use diverse habitats, ranging from seasonally dry tropical forest (SDTF) to wet forest, whereas others, such as the aquatic R. nasuta (Giraldo et al. 2012) and terrestrial Rhinoclemmys rubida (this study), are only found in specific habitat types.

Mexican Spotted Wood Turtles (R. rubida) are endemic to SDTF of western Mexico. Seasonally dry tropical forests are defined by strong seasonality in annual precipitation, resulting in a dry season of $4-8 \mathrm{mo}$, during which $<10 \%$ of annual precipitation occurs (Bullock et al. 1995; Dirzo et al. 2011). The evolutionary response to this strong seasonality has contributed to a unique flora and fauna with a great variety of plant life forms and animal adaptations that can withstand the intense seasonal drought, creating a remarkable concentration of endemic species (Borchert 1994; Ceballos and Brown 1995; García 2006; Dirzo et al. 2011). SDTF comprise almost half of the world's tropical forests, representing a larger fraction than wet forests, and provide a set of ecosystem services that rival wet forests because their soils are more fertile than those of wet forests (Murphy and

\footnotetext{
1 Correspondence: e-mail, taggertbutterfield3@gmail.com

2 Present Address: Estación de Biología Chamela, Instituto de Biología, Universidad Nacional Autónoma de México, Jalisco 48980, México
}

Lugo 1986; Maass et al. 2005; Blackie et al. 2014). Despite their importance, SDTFs are possibly the most threatened and least studied of the world's forested ecosystems (Janzen 1988; Miles et al. 2006; Portillo-Quintero and SánchezAzofeifa 2010).

The ways in which organisms respond to seasonal drought provide a contextual background for the predicted responses of many species to climate change in the tropics and other biomes (Meir and Pennington 2011; Valenzuela-Ceballos et al. 2015), where most climate models predict increases in temperature and seasonality (Solomon et al. 2007). Tropical dry forests comprise an important habitat type for geomydid turtles worldwide, yet we know little of the ecology of any geomydid species that inhabit these forests. How do these turtles respond to the strong seasonality? To what extent are neotropical geoemydids vulnerable to habitat fragmentation, overexploitation, and climate change occurring throughout their range? Simple questions like these remain to be answered because the ecology of turtle species in this ecosystem is still poorly known. Yet, their adaptations and responses to extreme seasonality are central to understanding the evolution and function of seasonal tropical environments (Ceballos and García 1995; Dirzo et al. 2011; Stoner and Timm 2011).

Rhinoclemmys rubida comprises two extant subspecies, $R$. rubida perixantha (distributed from Nayarit-Michoacán) and $R$. rubida rubida (from Guerrero-Northern Guatemala; Legler and Vogt 2013). What little is known of the ecology of this species comes from a handful of field observations (Mosimann and Rabb 1953; Holcomb and Liu 2012; Butterfield and Rivera 2014), or from captive individuals (Holcomb and Liu 2012; Legler and Vogt 2013). To address this knowledge gap, our study focused on activity patterns, home range, and microhabitat use of $R$. $r$. perixantha in coastal Jalisco, Mexico. Our objectives were (1) to determine daily and seasonal patterns of activity, (2) to estimate home range size, and (3) to evaluate habitat use by $R$. $r$. perixantha by identifying microhabitat variables associated with their presence in SDTF. Knowledge of the autecology of $R$. 
rubida can provide insight into how vertebrate ectotherms of the SDTFs thrive in the wake of its strong seasonality, as well as crucial information for the long-term management of this and other threatened species of the SDTF.

\section{Materials and Methods}

\section{Study Area}

Our study site was the Estación de Biología Chamela (EBCh), a field station located on the Pacific Coast of Mexico within the $16-\mathrm{km}^{2}$ biological Chamela-Cuixmala Biosphere Reserve in Jalisco, Mexico. Vegetation at EBCh was comprised of a lowland SDTF, with a climate showing marked seasonality in precipitation $(80 \%$ of the mean annual precipitation of $800 \mathrm{~mm}$ normally falls during the 4-mo wet season of July-October; Maass et al. 2017). Mean annual temperature of $24.9^{\circ} \mathrm{C}$ ranges from a monthly nighttime low of $14.8^{\circ} \mathrm{C}$ (February) to a daytime high of $32.0^{\circ} \mathrm{C}$ (August). The landscape throughout $\mathrm{EBCh}$ is undulating with elevations ranging from 30 to $140 \mathrm{~m}$. The topography creates a diversity of microenvironments within the forest, most notably a semideciduous forest in the arroyos, and a fully deciduous forest in the uplands (Lott et al. 1987; Durán et al. 2002).

\section{Monitoring Turtles}

Experimenters sought turtles by walking along and off trails in potential turtle habitat between October 2014 and October 2016. Turtles were captured by hand, and each individual was uniquely marked with combinations of notches on the marginal scutes with the use of a triangular file (Cagle 1939). We measured carapace and plastron dimensions $( \pm 0.1 \mathrm{~mm})$, sex, mass, age class (juvenile, subadult, adult), initial capture location (UTM), activity status (active/inactive), and microhabitat features. To record turtle movements, we equipped a subset of individuals $(>70$ $\mathrm{mm}$ straight-line carapace length [CL]) with either nylon cocoon bobbins or radio transmitters and monitored these every 1-3 d throughout the study period (see Appendix I for monitoring periods).

Nine individuals (three males, six females) monitored during the first $8 \mathrm{mo}$ of the study (November 2014-June 2015) were equipped with nylon cocoon bobbins (Danfield Limited, Lancashire, UK). Bobbins contain $250 \mathrm{~m}$ of textile nylon thread and were attached to the rear marginal scutes of the carapace with epoxy putty, as described in Wilson (1994). We attached thread at the end of each spool to a nearby tree and as the individual walked through the forest thread was thereby laid down, recording the turtle's path and location. When less than half of the thread remained in each bobbin, it was replaced to ensure continuous monitoring. Bobbins were removed during May and June as turtles began making more frequent, larger forays to avoid losing individuals with attached bobbins. No turtles became entangled with the line. One bobbin was found detached from the turtle with bite and/or claw marks and the fate of that turtle is unknown.

At the onset of the wet season (June-July 2015), 12 adults (6 previously monitored with bobbins and 6 new adults) were outfitted with VHF radio transmitters. To provide a representative sample of both sexes, six males and six females were equipped with transmitters and monitored until September 2015 (Appendix I). Radio transmitters weighed either 6 or $10 \mathrm{~g}$ (RI-B2, Holohil, Inc.) with battery lives of approximately $6 \mathrm{mo}$ ( $6 \mathrm{~g}$ radio) to $1 \mathrm{yr}$ ( $10 \mathrm{~g}$ radio). Transmitters were attached to the front (female) and rear (male) marginal scutes with epoxy putty. Individuals were located with the use of a Telonics TR-2 receiver and a handheld "H" antenna (150-154 MHz, Telonics, Inc.). Turtles were located every 1-3 d. Each radio weighed less than $7 \%$ of each turtle's mass.

\section{Activity Patterns}

Daily timing of activity was summarized from records of turtles directly observed in the field. Turtles were considered active if they were alert on the surface, and inactive if they were buried in leaf litter, woody debris, vegetation, or inside a shelter. Because turtles could not always be observed directly, annual activity was assessed using movement as an indicator of activity bouts. "Movement" indicates that a turtle had moved from its previously observed location, and "No Movement" indicates that a turtle had remained at the same location. Straight-line distances between consecutive relocations were used to describe the spatial extent of activity bouts between the sexes and seasons. Straight-line distances (means $\pm 95 \%$ CI) were determined by constructing trajectory plots with the as.ltraj function in the adehabitatLT package in $\mathrm{R}$ and exporting the associated data with the use of the write.xlsx function in the xlsx package (Appendix I; Calenge 2006; Dragulescu 2014; R Core Team 2016).

\section{Home Range}

From among the 12 telemetered adults, we estimated home range sizes for those subjects that were located more than 30 times (see Appendix I). Methods used to estimate home range can strongly influence interpretations of home range size, yet there is little agreement among researchers on the best method to estimate home range size (Laver and Kelly 2008; Gula and Theuerkauf 2013). Because of this, and to provide estimates that can be compared with past and future studies, we used three different methods to calculate home range: minimum convex polygon (MCP; Hayne 1949), fixed $95 \%$ kernels ( $\mathrm{K}_{95 \%}$; Worton 1989), and 95\% Brownian bridge kernels ( $\mathrm{BB}_{95 \%}$; Bullard 1999), all estimated using the adehabitatHR package in $\mathrm{R}$ (Calenge 2006; $\mathrm{R}$ Core Team 2016)

The MCP method (function MCP) involves drawing the smallest polygon that encompasses all of an individual's recorded locations (Hayne 1949). $\mathrm{K}_{95 \%}$ (function kernel) estimates produce a spatial distribution based on the likelihood of finding an animal in any particular location within its home range (Worton 1989). We used least-squared cross validation (LSCV) to determine the smoothing parameter ( $\mathrm{h}$ ) for our $\mathrm{K}_{95 \%}$ estimates because this technique has produced consistent results in other studies (Worton 1989; Seaman and Powell 1996; Morzillo et al. 2003, but see Row and Blouin-Demers 2006 for discussion on inconsistencies of $\mathrm{K}_{95 \%}$ with herpetofauna). $\mathrm{BB}_{95 \%}$ (function kernelbb) estimation is a relatively new extension of the kernel density to estimate home range (Bullard 1999). $\mathrm{K}_{95 \%}$ treats consecutive locations as independent observations, whereas the $\mathrm{BB}_{95 \%}$ considers time spent between locations, permitting one to assess an organism's use of habitat in both space and time (Bullard 1999; Horne et al. 2007). BB $_{95 \%}$ was originally 
designed for serial autocorrelated locations collected with satellite GPS transmitters and is generally not considered appropriate for VHF telemetry where consecutive observations might be separated by several days. Here, we located turtles every 1-3 d, with a total of 680 separate observations (average number of observations per turtle $=56.7$, average number of days between observations $=2.5 \mathrm{~d}$ ). Because turtle locations averaged less than $3 \mathrm{~d}$ apart, we felt that use of $\mathrm{BB}_{95 \%}$ would be useful and appropriate in our system. Unlike $\mathrm{K}_{95 \%}$ estimates that require a smoothing factor $(\mathrm{h})$ to estimate home range, however, $\mathrm{BB}_{95 \%}$ requires the input of sigl, which is related to the speed of the animal, and sig2, which is related to the imprecision of the locations (Calenge 2006). Although sigl can be determined with the use of maximum likelihood with the liker function in adehabitatHR package, this function requires sig2 and there is currently no method to select this parameter. We selected sig2 based on the technique presented in the vignette for adehabitatHR package, where sig2 was set to equal the standard deviation of individual locations (Calenge 2006). Our method differed slightly because, instead of using standard deviation, we set sig2 to equal the size of the $95 \%$ confidence interval of mean straightline distance for each individual (e.g., the distance moved for Turtle 6 was $36.82 \pm 8.39 \mathrm{~m}$, so we set sig $2=8.39$ for Turtle 6 ). Then, we calculated sigl with the liker function within the adehabitatHR package. In every case, sigl was estimated to be between 0 and 0.5 . Therefore, we set sigl to 0 in all cases because the kernelbb function only accepts whole numbers for sigl.

\section{Microhabitat}

We quantified microhabitat features of unique locations used by turtles, and of random locations throughout the Chamela forest. Only locations of inactive turtles were used to reduce the ambiguity associated with the particular microhabitats that turtles selected when moving. At least 12 unique turtle locations and 12 random locations were characterized each month from April to September 2015, totaling 153 plots (83 turtle locations and 70 random locations). Unique turtle locations were selected randomly from observations made within each respective month (no location was measured more than once) and random locations were selected for comparison by choosing points (using a random number generator) along the $13 \mathrm{~km}$ of trails in the Chamela forest and walking a random distance (1-30 $\mathrm{m})$ in a random direction $\left(0-360^{\circ}\right)$ from those points.

At each point, we centered a $1 \times 1-\mathrm{m}$ plot over the microhabitat and estimated percent ground cover of woody debris, bare ground, leaf litter, rock, vines, vine-like shrubs, trees (ground cover of trees with diameter at breast height $[\mathrm{dbh}]>10 \mathrm{~cm}$ ), and herbaceous plants. We also recorded slope with a clinometer, canopy cover at 10 and $150 \mathrm{~cm}$ with a spherical densiometer, and aspect with a compass at each location. Random locations were selected along trails because at $\mathrm{EBCh}$, these $13 \mathrm{~km}$ of trails capture a representative sample of different habitat types within the forest (Lott et al. 1987), and the thick understory of the Chamela forest precludes access to other locations.

\section{Statistical Analysis}

We report mean values $\pm 95 \%$ confidence interval. All statistical analyses were done in R (R Core Team 2016), with significance assessed at $\alpha=0.05$. A general linear mixed model (LMM) was used to determine the effect of season, sex, and their interaction on straight-line distances moved by turtles. Straight-line distance (response variable) was modeled as a function of sex, season, and the interaction between sex and season (independent variables) with turtle as a random effect with the use of the lme function in the nlme package (Pinheiro et al. 2016). A Shapiro-Wilk test (function shapiro.test, package stats; R Core Team 2016) was used to test for normality of standardized residuals. In addition, standardized residuals were plotted as a function of each independent variable to visually assess homogeneity of variances. The final straight-line distance model was compared to a null model with a likelihood-ratio test (LRT) to determine fit of the model (function anova; $\mathrm{R}$ Core Team 2016). $P$ values of individual coefficients (sex, season, sex * season) were also calculated with the use of a LRT.

A general linear model (LM) was used to test for differences among the three different methods used to calculate home range. We used the $\mathrm{lm}$ function in package stats to model home range size (explanatory variable) as a function of the method used (independent variable). Standardized residuals were plotted to assess homoscedasticity visually and subjected to a Shapiro-Wilk test to assess normality (function shapiro.test). The anova function in package stats was used to calculate the corresponding $F$ statistics and $P$ values. To compare the home range sizes between sexes, we used three separate two-sample $t$-tests for each home range method (function t.test; $\mathrm{R}$ Core Team 2016).

A generalized linear model (GLM, link = logit) was used to test for differences in microhabitat variables (independent variables) between random locations and locations where turtles were found (binomial response variable; function glm; R Core Team 2016). A full model analysis was used in place of stepwise model selection because stepwise model selection procedures have several recognized drawbacks, including reliance on a single reduced model (Whittingham et al. 2006). Because of these drawbacks, we performed a full model analysis to assess the relative importance of each microhabitat variable in the model. However, microhabitat variable Tree (percent ground cover of trees $>10 \mathrm{~cm} \mathrm{dbh}$ ) was removed from the analysis because of the low number of observations. This also avoids issues that arise when predictor variables are constrained to a constant sum (all qualitative microhabitat variables measured in a $1 \times 1-\mathrm{m}$ plot sum to 100). Other microhabitat variables were only dropped from the model if they were significantly collinear with other variables. Collinearity was tested with variance inflation factors-values greater than 5 indicate high collinearity with other independent variables and were removed from the model (function vif, package car; Fox and Weisberg 2011). An LRT between the full and null model was calculated to determine if the full model significantly explained patterns of variation in the data (function anova, package stats; R Core Team 2016). A McFadden's pseudo $R^{2}(100 \times$ [null deviance - residual deviance]/null deviance) was calculated to assess how well the model explains the variation in the data. Then, an LRT was calculated to determine the importance of each microhabitat variable in the full model (function drop1; $\mathrm{R}$ 


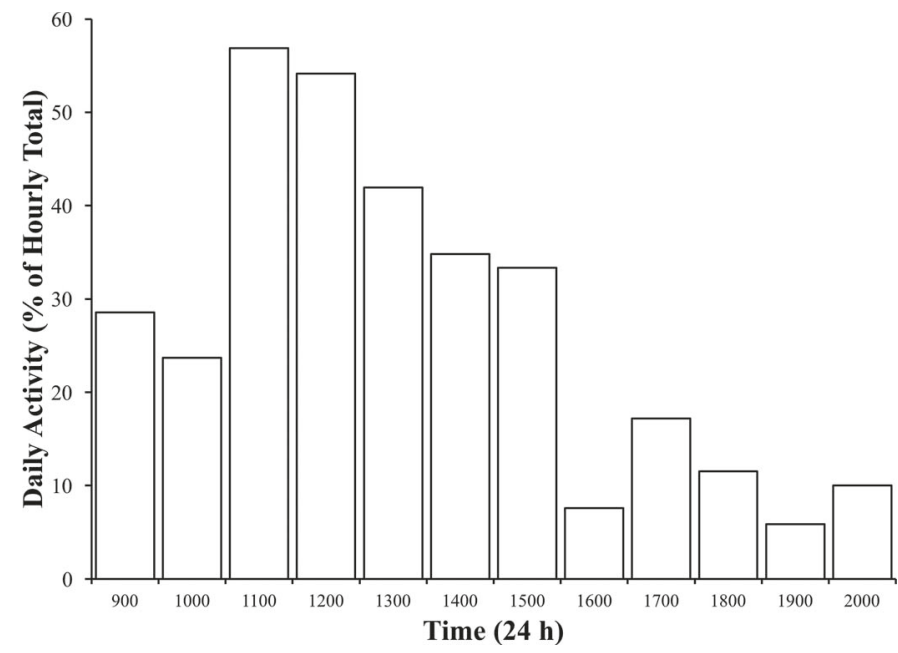

FIG. 1.-Percent of total observations within each hour that comprised the activity of Rhinoclemmys rubida perixantha in the Estación de Biología Chamela, Jalisco, Mexico, after correcting for sampling effort $(n=204)$. No data were recorded from 2000 to $0900 \mathrm{~h}$.

Core Team 2016). These values follow a chi-square distribution and are used to test the significance of the full model and the nested models. We report LRT test statistic values and their associated $P$ values for each microhabitat variable.

\section{RESUlts}

\section{Population Characteristics}

One hundred thirty-four individual $R$. $r$. perixantha were captured, measured, and released during the study period (November 2014-October 2016). Males were encountered most frequently $(n=65)$, followed by females $(n=51)$ and juveniles $(n=18)$. Individuals in this population exhibited sexual size dimorphism, with females being larger than males in both CL (females $=122 \pm 1.9 \mathrm{~mm}$, males $=98 \pm 1.6$ $\mathrm{mm}$, juveniles $=63 \pm 2.9 \mathrm{~mm} ; t=7.78, P<0.0001)$ and mass (females $=287 \pm 12.5 \mathrm{~g}$, males $=144 \pm 4.3 \mathrm{~g}$, juveniles $=42 \pm 4.5 \mathrm{~g} ; t=-9.25, P<0.0001)$.

\section{Activity Patterns}

Rhinoclemmys $r$. perixantha at EBCh show considerable diurnal activity, with most turtle activity occurring between 900 and $1500 \mathrm{~h}$, and the least between 1600 and $2000 \mathrm{~h}$ (Fig. 1). Because we did not systematically sample the timing of movement at night, we were not able to investigate nocturnal activity adequately; no data are available from 2100 to 0900 h.

Rhinoclemmys $r$. perixantha monitored in this study showed greater activity during the wet season (JuneSeptember; Fig. 2). During this time, turtles changed locations between $94 \%$ of all observations (445 of 474). During the dry season, turtles changed locations between $28 \%$ of all observations (79 of 366). Dry-season precipitation in November, February, and March 2015 was abnormally high (see below), but did not result in a marked increase in movements as observed during the wet-season months of June-September (Fig. 2).

Straight-line distances (Appendix II) were square-root transformed in an attempt satisfy the LMM assumption of

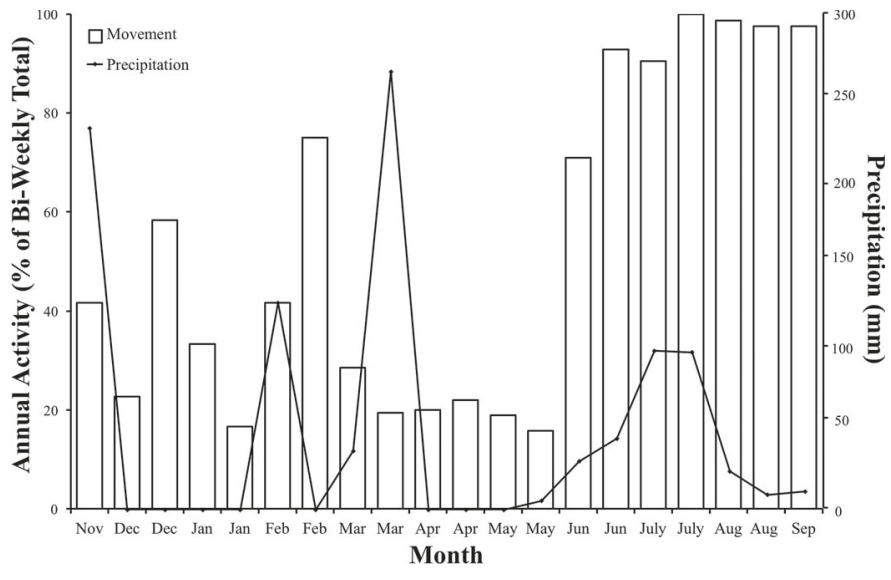

FIg. 2.-Annual activity of Rhinoclemmys rubida perixantha from November 2014-September 2015, after correcting for sampling effort. Bars are biweekly representations of the percentage of turtle observations that comprise Movement ( $n=970$; see Methods) and lines represent total biweekly precipitation throughout the study period. No data were collected in October.

normality, but five outliers prevented the data from being normal (Shapiro-Wilk test, $W=0.99, P=0.002$ ). These outliers were the result of two male subjects (turtles 16 and 17) walking long straight-line distances $(>170 \mathrm{~m})$. Although removing these outliers made the data normal, including them in the model did not change the result. Variation of residuals was homoscedastic among sex, season, and individual turtles. The final model explained variation in straight-line distances among sex, season, and sex * season when compared to the null model $($ LRT $=68.04, P<$ 0.0001). Turtles traveled farther during the wet season than the dry season $\left(F_{18,486}=70.99, P<0.0001\right.$, LMM $)$. There was no difference in distances moved between sexes $\left(F_{18,486}\right.$ $=3.98, P=0.06, \mathrm{LMM})$ and no significant interaction between season and $\operatorname{sex}\left(F_{18,486}=2.48, P=0.12, \mathrm{LMM}\right)$.

\section{Home Range}

Home range size was log transformed to meet the assumption of normality (Shapiro-Wilk test, $W=0.95, P$ $=0.12$ ) and visual analysis of standardized residuals show that these data were homoscedastic. There was no difference in home range size among the three methods used to calculate home range $\left(F_{3,12}=0.58, P=0.57\right.$, LM; Table 1$)$. With the use of the MCP and $\mathrm{K}_{95 \%}$ estimates, the home range size of male turtles was similar to that of females (MCP: $t_{6,6}=-1.72, P=0.14 ; \mathrm{K}_{95 \%}: t_{6,6}=-2.05, P=0.09$ ). For the $\mathrm{BB}_{95 \%}$, male home ranges were larger than females $\left(t_{6,6}=-2.82, P=0.03\right)$.

\section{Microhabitat}

Values for the microhabitat variables (woody debris, bare ground, leaf litter, rock, vines, vine-like shrubs, trees [dbh $>$ $10 \mathrm{~cm}$ ], herbaceous plants) were arcsine transformed. The microhabitat variable Leaf Litter had a variance inflation factor greater than 5 and was removed from the model. The global model differed from the null model (null deviance $=$ 206.01 on $149 \mathrm{df}$, residual deviance $=143.05$ on $138 \mathrm{df} ; \chi^{2}=$ $62.99, P<0.001)$ and explained $30.5 \%$ of the variation in the data (McFadden's pseudo $R^{2}$ ). Values for rock, aspect, cover at $10 \mathrm{~cm}$, and cover at $150 \mathrm{~cm}$ indicate that these variables 
TABLE 1.-Mean ( $\pm 95 \%$ confidence interval) home ranges (ha) for each sex of Rhinoclemmys rubida perixantha at Estación de Biología Chamela, Jalisco, Mexico, as calculated using minimum convex polygon (MCP), 95\% kernel density $\left(\mathrm{K}_{95 \%}\right)$, and $95 \%$ Brownian bridge $\left(\mathrm{BB}_{95 \%}\right)$ estimators. Minimum and maximum values are given in parentheses below each estimate.

\begin{tabular}{lcccc}
\hline Sex & & & Home range (ha) & \\
\hline Female & 6 & $0.50 \pm 0.26$ & $0.63 \pm 0.16$ & $0.55 \pm 0.19$ \\
& & $(0.26-0.96)$ & $(0.41-0.82)$ & $(0.31-0.78)$ \\
Male & 6 & $1.02 \pm 0.65$ & $2.07 \pm 1.72$ & $1.26 \pm 0.59$ \\
& & $(0.31-2.23)$ & $(0.50-5.34)$ & $(0.37-2.12)$ \\
Total & \multirow{2}{*}{12} & $0.92 \pm 0.41$ & $1.35 \pm 0.88$ & $0.90 \pm 0.35$ \\
& & $(0.26-0.96)$ & $(0.41-5.34)$ & $(0.31-2.12)$ \\
\hline
\end{tabular}

were not associated with turtle presence (Table 2). In contrast, values for bare ground, woody debris, vines, vinelike shrubs, herbaceous plants, and slope were positively associated with turtle presence, whereas bare ground was negatively associated with turtle presence (Table 2).

\section{Discussion}

\section{Activity Patterns}

Activity patterns of $R$. r. perixantha varied daily and seasonally. In general, turtles in the Chamela forest showed a unimodal pattern of diurnal activity, with a peak between 0900 and $1500 \mathrm{~h}$ (although no nocturnal data were available). This pattern of daily activity matches that of other small, forest-dwelling turtles (Ellner and Karasov 1993; Chen and Lue 2008; Zai-Zhong et al. 2016), but differs from those of small turtles living in semiarid grasslands and desert environments. For example, Desert Box Turtles (Terrapene ornata luteola) living in semiarid grasslands and arid deserts show a bimodal pattern in activity comprising morning $(0600-0900 \mathrm{~h})$ and late afternoon peaks $(1600-1800 \mathrm{~h}$; Nieuwolt 1996; Plummer 2003). This is likely because such habitats experience high midday temperatures that force turtles to remain inactive to avoid overheating (Nieuwolt 1996; Plummer 2003). The shaded forest canopy of the SDTF inhabited by $R$. $r$. perixantha likely moderates midday temperatures and allows turtles to remain active throughout the day.

Even though the wet season of 2015 received among the scantest precipitation on record (EBCh climate data), turtles showed greater activity, and walked longer distances, during the wet season than the dry season (Fig. 2). Typically, the dry season in the SDTF of Chamela spans from November through mid-June, with $80 \%$ of annual precipitation falling during the wet season from mid-June through October. During the dry season of 2015, however, our study site received unusually large amounts of precipitation $(654 \mathrm{~mm}$, or $82 \%$ of the annual $800-\mathrm{mm}$ average). Most notable was the $299 \mathrm{~mm}$ of precipitation from a storm in March, normally among the driest months of the year. Although turtles moved following these rains, they did so less frequently and walked shorter distances than during the more typical wet season months of June-September. Guapira macrocarpa, a known resource for turtles that typically fruits following the first wet season rains, did not fruit in response to these abnormal dryseason rains (Durán et al. 2002; Butterfield and RiveraHernandez 2014; TGB, personal observation). This apparent
TABLE 2.-Results from generalized linear model (link = logit) with presence (turtle and random locations) modeled as a function of the microhabitat variables measured at Estación de Biología Chamela, Jalisco, Mexico, from April to September 2015. Coefficients were calculated with the glm function in the stats package; likelihood ratio and $P$ values for each variable were calculated with the dropl function in package stats.

\begin{tabular}{lccc}
\hline Microhabitat variable & Coeffecient & Likelihood ratio & $P$ \\
\hline Intercept & -10.93 & & \\
Bare ground & -3.77 & 9.56 & $<0.01$ \\
Woody debris & 3.74 & 8.14 & $<0.01$ \\
Rock & 1.27 & 0.58 & 0.45 \\
Vines & 3.98 & 9.84 & $<0.01$ \\
Vine-like shrub & 6.02 & 21.93 & $<0.001$ \\
Herbaceous plant & 3.19 & 3.90 & $<0.05$ \\
Aspect & $-1.4 \times 10^{-5}$ & $1.00 \times 10^{-4}$ & 0.99 \\
Slope & 0.12 & 28.80 & $<0.001$ \\
Canopy cover at $10 \mathrm{~cm}$ & $-9.26 \times 10^{-3}$ & 0.02 & 0.89 \\
Canopy cover at $150 \mathrm{~cm}$ & 0.07 & 2.03 & 0.13 \\
\hline
\end{tabular}

lack of activity by turtles (and response of one of their important food sources) following intense dry season rain, coupled with their increase in activity following the first rain of the wet season, indicate that turtles in the SDTF of Chamela might be responding to strong seasonal patterns shaped by evolution, rather than mere proximal cues based solely on precipitation.

During the dry season at our study site, $R$. $r$. perixantha moved shorter straight-line distances, on average, and spent most days inactive. The lack of resources during the dry season forces turtles and other organisms to subsist 6 mo or more with little to no food or water (Murphy and Lugo 1986). Plants overcome this challenge by shedding their leaves and desiccating, or storing water (Bullock and SolisMagallanes 1990; Borchert 1994); many insect species go dormant (Danks 1987); other reptile species (e.g., Heloderma horridum) estivate and can use fat reserves to access energy when needed (Beck and Lowe 1991). Although turtles in our study probably remained inactive to conserve energy and minimize water loss, empirical studies on drought tolerance have been conducted only with other species (Ligon and Peterson 2002; Penick et al. 2002). Ligon and Peterson (2002) found that the response to dehydration in three species of mud turtle is highly dependent on behavior. The species that reduced activity the most (Kinosternon flavescens) exhibited reduced resting metabolic rates and increased water retention during dehydration experiments. In contrast, species that are more active $(K$. hirtipes and $K$. sonoriense) had higher resting metabolic rates and reached near-lethal levels of dehydration after $30 \mathrm{~d}$ (Ligon and Peterson 2002). In field settings, inactive Box Turtles (Terrapene carolina) have lower resting metabolic rates and lower water flux rates during winter and spring when resources are less abundant (Penick et al. 2002). Future studies might investigate whether $R$. $r$. perixantha shows a similar pattern of lower metabolic rates and reduced water flux rates to endure the long dry season with little access to food or water.

\section{Home Range}

A lack of consensus remains on the most appropriate method for calculating home range sizes (Laver and Kelly 2008; Gula and Theuerkauf 2013). There were no differences among the home range sizes estimated from the three 
common methods that we applied to data for $R$. $r$. perixantha. The mean home range size of $R$. r. perixantha at our study site $(0.9 \mathrm{ha})$ is smaller than those of other terrestrial turtles in general (mean $=20.1$ ha; Slavenko et al. 2016). As examples, Clemmys guttata, Graptemys flavimaculata, and $T$. ornata have mean straight-line carapace lengths of $\sim 160 \mathrm{~mm}$, similar to $R$. $r$. perixantha (mean $=120$ $\mathrm{mm}$ ), yet the three species have a mean home range of $\sim 3.7$ ha (Slavenko et al. 2016).

Small body size might partially explain the small home range size of $R$. r. perixantha, but the structure of the SDTF habitat is likely also important. Unlike seasonal rainforest, the more open canopy in SDTF creates a dense, tangled understory with many obstacles on the ground. This, along with the diverse topography, makes moving across the landscape energetically costly for turtles, and possibly restricts them from occupying larger areas. Also, the density of food resources (e.g., cacti, arthropods) in SDTF might be high, allowing $R$. r. perixantha to exist within smaller areas than those turtle species occurring in less productive habitats (Legler 1960; Murphy and Lugo 1986). For example, turtle species living in sparsely vegetated habitats with less topographic diversity and less (or patchier) resource availability (e.g., deserts) tend to be larger and occupy larger home ranges (e.g., Gopherus morafkai; Sullivan et al. 2016). Taken together, habitat structural complexity and food availability likely both contributed to defining the area occupied by a particular turtle species, and these same characteristics have likely influenced their evolution.

\section{Microhabitat}

Leaf litter was removed from our microhabitat analysis because it was collinear with other variables. We attempted to remove other microhabitat variables before removing leaf litter; however, the variance inflation factor (VHF) for leaf litter remained very high when removing other variables. This was unfortunate, because, among direct field observations (not microhabitat analysis), turtles were observed in leaf litter $60.1 \%$ of the time, followed by woody debris $(22.5 \%)$, vegetation $(10.1 \%)$, and shelters $(7.3 \% ; n=456)$. The collinearity of leaf litter with other independent variables in the microhabitat analysis is likely a result of sampling microhabitat within $1 \times 1-\mathrm{m}$ plots. At this scale, increases in leaf litter corresponded to decreases in the other variables. Therefore, the removal of leaf litter from this analysis should be interpreted as an artifact of our sampling technique rather than its importance to $R$. $r$. perixantha.

Rhinoclemmys $r$. perixantha radiotracked in this study sought refuge on hillsides that had at least one of several vegetative features on the forest floor, including woody debris, vegetation (vines, vine-like shrubs, herbaceous plants), and leaf litter (Fig. 3). Our microhabitat analysis indicated that turtles select such microhabitat components at greater proportions relative to their availability, and that turtles tend to avoid areas having higher percentages of bare ground. These results are consistent with other forestdwelling terrestrial turtles, including Cuora flavomarginata (Geoemydidae), and T. ornata and T. carolina (Emydidae), which retreat to similar microhabitats, usually consisting of vegetation and debris on the forest floor (Reagan 1974; Lue and Chen 1999; Converse and Savage 2003; Rossell et al. 2006).
The body plan of terrestrial forest turtles restricts them from occupying microhabitats immediately above the surface. Some terrestrial species have become specialized to particular microhabitats, such as the crevice-dwelling Pancake Tortoise (Malacochersus tornieri), but small forestdwelling turtles tend to be generalists with respect to microhabitats at the surface (Xia et al. 1983; Lue and Chen 1999; Vogt et al. 2009; Xiao et al. 2017). Structural characteristics on the SDTF forest floor include herbaceous vegetation, vines, shrubs, woody debris, leaf litter, burrows, trees (included fallen trees), or rocky outcrops. The importance of any of these structural components to a turtle lies in its ability to provide protection from predators and environmental extremes (Reagan 1974). Microhabitats used by turtles must also have environmental properties suitable for thermoregulation and avoiding dehydration (Reagan 1974; Rossell et al. 2006). In this study, woody debris and vine-like shrubs, coupled with sloped terrain $(\bar{X}=25 \%$ grade), tended to promote the accumulation of mixed clumps of leaf litter used by $R$. r. perixantha. These microhabitats provided refuge, relatively stable temperatures and potentially increased relative humidity for turtles in the STDF during the dry season (Fig. 3).

To our knowledge, this is the first intensive field study of a geoemydid turtle in a neotropical dry forest. Our results indicate that $R$. r. perixantha manages the strong seasonality of the STDF habitat in part by adjusting its patterns of activity to coincide with the seasonal availability of resources during the wet season, and remaining less active throughout the dry season. These turtles have small home ranges atop and along the undulating hills in the Chamela forest. Even with this information, much remains to be learned about the ecological role that these turtles have in the SDTF.

Rhinoclemmys $r$. perixantha appears far more abundant in the Chamela forest than prior observations suggest (e.g., van Dijk et al. 2007; Holcomb and Liu 2012). We examined 134 subjects during our study, and approximately 100 additional individuals have been encountered since that time (TGB, personal observation). Moreover, fecal samples from some subjects revealed that at least seven different species of plants are consumed by $R$. $r$. perixantha, including Ficus sp., Opuntia sp., G. macrocarpa, and four other unidentified species (TGB, personal observation). Therefore, given their abundance and potential for dispersing seeds, $R$. $r$. perixantha might provide an important ecosystem services that has seldom been quantified in turtles (but see Jones et al. 2007).

The reliance of $R$. r. perixantha upon crucial components of the forest floor (herbaceous vegetation, vines, shrubs, woody debris, leaf litter, burrows) highlights the importance of understory structural diversity within the tropical dry forest. Knowledge of habitat features and activity patterns that are important to the biology of $R$. $r$. perixantha might inform management and restoration efforts, but can also aid in understanding ecological disturbance in tropical dry forests. For example, the strong winds of Hurricane Patricia $(209-251 \mathrm{~km} / \mathrm{h})$, which struck the field station in October 2015 , altered the structure of the forest by depositing large quantities of woody debris on the forest floor (González del Castillo 2016; Martínez-Ruiz and Renton 2017). Because of the importance of woody debris to the turtles in this study, as well as many other species that inhabit the understory, 

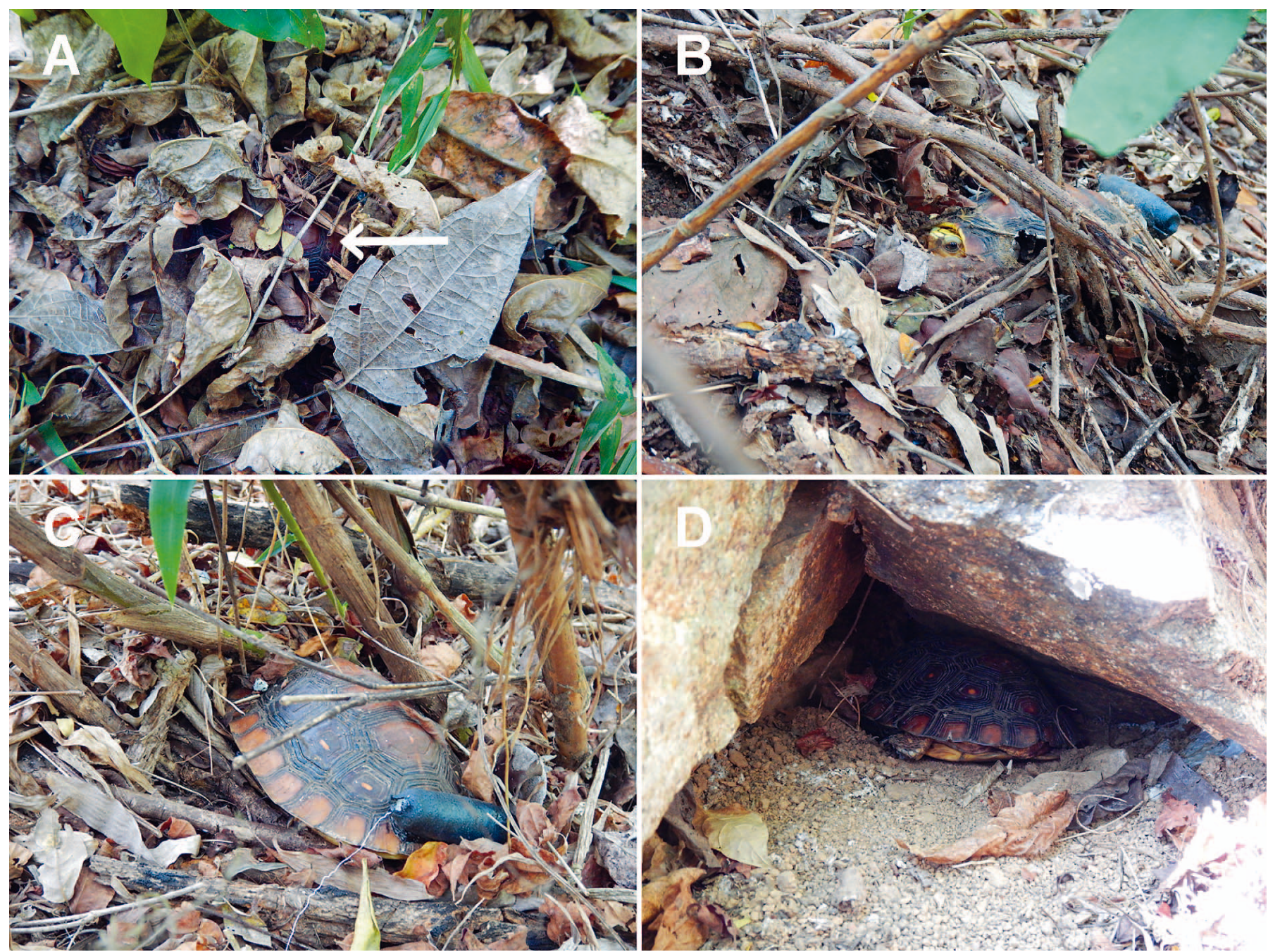

Fig. 3.-Rhinoclemmys rubida perixantha taking refuge in (A) leaf litter, (B) woody debris, (C) vine-like shrub, and (D) shelter (rock) in the seasonally dry tropical forest of Chamela, Jalisco, Mexico. White arrow indicates location of turtle in panel A.

knowledge of their habitat use and movements through the forest can allow ecologists to predict how tropical forests might recover from increasingly stronger tropical storms associated with global climate change (Knutson et al. 2010).

Acknowledgments.-We thank J. Rivera-Vega and K. Renton, along with the rest of the EBCh staff, for supporting TGB during his time at the Chamela field station, and for their logistical assistance. Thanks to our colleagues at Central Washington University (CWU), most notably J. Betz, L. Ely, K. Ernest, K. Holcomb, and G. Scoville. Special thanks to the Rufford Foundation, CWU School of Graduate Studies and Research, and NSF award 1559447 (IRES SOBRE Mexico) for financial and logistical support of this project. This study was conducted under UNAM research permits to AGA and a CWU Institutional Animal Care and Use Committee (IACUC) protocol to TGB and DDB (A121402). We thank the Editor, Associate Editor, and two anonymous reviewers whose comments improved this manuscript.

\section{Literature Cited}

Beck, D.D., and C.H. Lowe. 1991. Ecology of the beaded lizard, Heloderma horridum, in a tropical dry forest in Jalisco, Mexico. Journal of Herpetology 25:395-406.

Blackie, R., C. Baldauf, D. Gautier . . . T. Sunderland. 2014. Tropical Dry Forests: The State of Global Knowledge and Recommendations for Future Research, vol. 2. CIFOR, Indonesia.
Borchert, R. 1994. Soil and stem water storage determine phenology and distribution of tropical dry forest trees. Ecology 75:1437-1449.

Bullard, F. 1999. Estimating the Home Range of an Animal: A Brownian Bridge Approach. M.S. thesis, Johns Hopkins University, USA.

Bullock, S.H., and J.A. Solis-Magallanes. 1990. Phenology of canopy trees of a tropical deciduous forest in Mexico. Biotropica 22:22-35.

Bullock, S.H., H.A. Mooney, and E. Medina (eds.). 1995. Seasonally Dry Tropical Forests. Cambridge University Press, USA.

Butterfield, T.G., and O.F. Rivera-Hernandez. 2014. Natural history notes: Rhinoclemmys rubida perixantha (diet). Herpetological Review 45:320 321

Cagle, F.R. 1939. A system of marking turtles for future identification. Copeia 1939:170-173.

Calenge, C. 2006. The package adehabitat for the R software: A tool for the analysis of space and habitat use by animals. Ecological Modelling 197:516-519. DOI: http://dx.doi/org/10.1016/j.ecolmodel.2006.03.017.

Ceballos, G., and J.H. Brown. 1995. Global patterns of mammalian diversity, endemism, and endangerment. Conservation Biology 9:559-568.

Ceballos, G., and A. García. 1995. Conserving neotropical biodiversity: The role of dry forests in western Mexico. Conservation Biology 9:1349-1353.

Chen, T.H., and K.Y. Lue. 2008. Thermal preference of the yellowmargined box turtle (Cuora flavomarginata) (Testudines: Geoemydidae) inhabiting a mesic lowland forest, northern Taiwan. Amphibia-Reptilia 29:513-522.

Converse, S.J., and J.A. Savage. 2003. Ambient temperature, activity, and microhabitat use by ornate box turtles (Terrapene ornata ornata). Journal of Herpetology 37:665-670. 
Danks, H.V. 1987. Insect Dormancy: An Ecological Perspective. Biological Survey of Canada, Canada.

Dirzo, R., H.S. Young, and H.A. Mooney. 2011. Seasonally Dry Tropical Forests: Ecology and Conservation. Island Press, USA.

Dragulescu, A. 2014. xlsx: Read, write, format Excel 2007 and Excel 97/ 2000/XP/2003 files. R package Version 0.5.7. Available at http://CRAN.Rproject.org/package=xlsx. R Foundation for Statistical Computing, Austria.

Durán, E., P. Balvanera, E. Lott, G. Segura, A. Pérez-Jiménez, A. Islas, and M. Franco. 2002. Estructura, composición y dinámica de la vegetación. Pp. 443-472 in Historia Natural de Chamela (F.A. Noguera, J.H. VegaRivera, A.N. García-Aldrete, and M. Quesada-Avendaño, eds.). UNAM, Mexico.

Ellner, L.R., and W.H. Karasov. 1993. Latitudinal variation in the thermal biology of ornate box turtles. Copeia 1993:447-455.

Ernst, C.H. 1978. A revision of the Neotropical turtle genus Callopsis (Testudines: Emydidae: Batagurinae). Herpetologica 34:113-134.

Fox, J., and S. Weisberg. 2011. An R Companion to Applied Regression, 2nd ed. SAGE Publishing, USA.

García, A. 2006. Using ecological niche modelling to identify diversity hotspots for the herpetofauna of Pacific lowlands and adjacent interior valleys of Mexico. Biological Conservation 130:25-46.

Giraldo, A., M.F. Garces-Restrepo, J.L. Carr, and J. Loaiza. 2012 Population size and structure of the large-nosed wood turtle (Rhinoclemmys nasuta, Testudines: Geoemydidae) in an insular environment of the Colombian pacific region. Caldasia 34:109-125.

Gong, S.P., H.T. Shi, A.W. Jiang, J.J. Fong, D. Gaillard, and J.C. Wang. 2017. Disappearance of endangered turtles within China's nature reserves. Current Biology 27:R170-R171.

González del Castillo, E. 2016. La corta e intensa vida del huracán Patricia. ¿Cómo ves?, Revista de Divulgación de la Ciencia de la UNAM 207:1619.

Gula, R., and J. Theuerkauf. 2013. The need for standardization in wildlife science: Home range estimators as an example. European Journal of Wildlife Research 59:1-6.

Hayne, D.W. 1949. Calculation of size of home range. Journal of Mammalogy 30:1-18.

Holcomb, K., and J. Liu. 2012. An inspiring first encounter with a smal Mexican dry forest turtle. The Turtle 1:50-59.

Horne, J.S., E.O. Garton, S.M. Krone, and J.S. Lewis. 2007. Analyzing animal movements using Brownian bridges. Ecology 88:2354-2363.

Janzen, D.H. 1988. Tropical dry forests. The most endangered major tropical ecosystem. Pp. 130-137 in Biodiversity (E.O. Wilson, ed.) National Academy Press, USA.

Jones, S.C., W.J. Jordan IV, S.J. Meiners, A.N. Miller, and A.S. Methven. 2007. Fungal spore dispersal by the Eastern box turtle (Terrapene carolina carolina). American Midland Naturalist 157:121-126.

Knutson, T.R., J.L. McBride, J. Chan, K. Emanuel, G. Holland, C. Landsea, I. Held, J.P. Kossin, A.K. Srivastava, and M. Sugi. 2010. Tropical cyclones and climate change. Nature Geoscience 3:157-163.

Laver, P.N., and M.J. Kelly. 2008. A critical review of home range studies. Journal of Wildlife Management 72:290-298.

Legler, J.M. 1960. Natural History of the Ornate Box Turtle, Terrapene ornata ornata (Agassiz). University of Kansas, USA

Legler, J.M., and R.C. Vogt. 2013. The Turtles of Mexico: Land and Freshwater Forms. University of California Press, USA.

Ligon, D.B., and C.C. Peterson. 2002. Physiological and behavioral variation in estivation among mud turtles (Kinosternon spp.). Physiological and Biochemical Zoology 75:283-293.

Lott, E.J., S.H. Bullock, and J.A. Solis-Magallanes. 1987. Floristic diversity and structure of upland and arroyo forests of coastal Jalisco. Biotropica 19:228-235.

Lue, K.Y., and T.H. Chen. 1999. Activity, movement patterns, and home range of the yellow-margined box turtle (Cuora flavomarginata) in northern Taiwan. Journal of Herpetology 33:590-660.

Maass, J.M., P. Balvanera, A. Castillo . . A. Martínez-Yrizar. 2005. Ecosystem services of tropical dry forests: Insights from long-term ecological and social research on the Pacific Coast of Mexico. Ecology and Society 10:1-23.

Maass, M., R. Ahedo-Hernández, A. Araiza . . . J. Sarukhán. 2017. Longterm (33 years) rainfall and runoff dynamics in a tropical dry forest ecosystem in western Mexico: Management implications under extreme hydrometeorological events. Forest Ecology and Management. DOI: https://dx.doi.org/10.1016/j.foreco.2017.09.040

Martínez-Ruiz, M., and K. Renton. 2017. Habitat heterogeneity facilitates resilience of diurnal raptor communities to hurricane disturbance. Forest Ecology and Management. DOI: http://dx.doi.org/10.1016/j.foreco.2017. 08.004 .

Meir, P., and R.T. Pennington. 2011. Climatic change and seasonally dry tropical forests. Pp. 279-399 in Seasonally Dry Tropical Forests (R. Dirzo, H.S. Young, H.A. Mooney, and G. Ceballos, eds.). Island Press, USA.

Miles, L., A.C. Newton, R.S. DeFries . . J.E. Gordon. 2006. A global overview of the conservation status of tropical dry forests. Journal of Biogeography 33:491-505.

Morzillo, A.T., G.A. Feldhamer, and M.C. Nicholson. 2003. Home range and nest use of the golden mouse (Ochrotomys nuttalli) in southern Illinois. Journal of Mammalogy 84:553-560.

Mosimann, J., and G. Rabb. 1953. A new subspecies of the turtle Geoemyda rubida (Cope) from western Mexico. Occasional Papers of the Museum of Zoology University of Michigan 548:1-7.

Murphy, P.G., and E.A. Lugo. 1986. Ecology of tropical dry forest. Annual Review of Ecology and Systematics 17:67-88.

Nieuwolt, P.M. 1996. Movement, activity, and microhabitat selection in the western box turtle, Terrapene ornata luteola, in New Mexico. Herpetologica 52:487-495.

Penick, D.N., J. Congdon, J.R. Spotila, and J.B. Williams. 2002 Microclimates and energetics of free-living box turtles, Terrapene carolina, in South Carolina. Physiological and Biochemical Zoology 75:57-65.

Pinheiro, J., D. Bates, S. DebRoy, D. Sarkar, and R Core Team. 2016. nlme: Linear and Nonlinear Mixed Effects Models. R package, Version 3.1128.Available at http://CRAN.R-project.org/package=nlme. R Foundation for Statistical Computing, Austria.

Plummer, M.V. 2003. Activity and thermal ecology of the box turtle, Terrapene ornata, at its southwestern range limit in Arizona. Chelonian Conservation and Biology 4:569-577.

Portillo-Quintero, C.A., and G.A. Sánchez-Azofeifa. 2010. Extent and conservation of tropical dry forests in the Americas. Biological Conservation 143:144-155

R Core Team. 2016. R: A Language and Environment for Statistical Computing. Available at http://www.R-project.org. R Foundation for Statistical Computing, Austria.

Reagan, D.P. 1974. Habitat selection in the three-toed box turtle, Terrapene carolina triunguis. Copeia 1974:512-527.

Rossell, C.R., Jr., I.M. Rossell, and S. Patch. 2006. Microhabitat selection by Eastern Box Turtles (Terrapene c. carolina) in a North Carolina mountain wetland. Journal of Herpetology 40:280-284.

Row, J.R., and G. Blouin-Demers. 2006. Kernels are not accurate estimators of home-range size for herpetofauna. Copeia 2006:797-802.

Seaman, D.E., and R.A. Powell. 1996. An evaluation of the accuracy of kernel density estimators for home range analysis. Ecology 77:2075-2085.

Slavenko, A., Y. Itesc, F. Ihlow, and S. Meiri. 2016. Home is where the shell is: Predicting turtle home range sizes. Journal of Animal Ecology 85:106114

Solomon, S., D. Qin, M. Manning . . . H.L Miller. 2007. IPCC 2007 Summary for policymakers. Climate Change 2007:79.

Spinks, P.Q., H.B. Shaffer, J.B. Iverson, and W.P. McCord. 2004. Phylogenetic hypotheses for the turtle family Geoemydidae. Molecular Phylogenetics and Evolution 32:164-182.

Stoner, K.E., and R.M. Timm. 2011. Seasonally dry tropical forest mammals: Adaptations and seasonal patterns. Pp. 85-106 in Seasonally Dry Tropical Forests (R. Dirzo, H.S. Young, H.A. Mooney, and G. Ceballos, eds.). Island Press, USA.

Sullivan, B.K., A.K. Owens, K.O. Sullivan, and E.A. Sullivan. 2016. Spatial ecology of Sonoran desert tortoises (Gopherus morafkai): I. Fidelity in home range, refuge use and foraging behavior. Journal of Herpetology 50:509-519.

Turtle Conservation Coalition. 2011. IUCN/SSC Tortoise and Freshwater Turtle Specialist Group, Turtle Conservation Fund, Turtle Survival Alliance, Turtle Conservancy, Chelonian Research Foundation, Conservation International, Wildlife Conservation Society, and San Diego Zoo Global. Pp. 54 in Turtles in Trouble: The World's 25+ Most Endangered Tortoises and Freshwater Turtles-2011 (A.G.J. Rhodin, A.D. Walde, B.D. Horne, P.P. van Dijk, T. Blanck, and R. Hudson, eds.). Turtle Conservation Coalition, USA.

Turtle Taxonomy Working Group. 2017. Turtles of the World: Annotated Checklist and Atlas of Taxonomy, Synonymy, Distribution, and Conservation Status. Chelonian Research Monographs 7:1-292.

Valenzuela-Ceballos, S., G. Castañeda, T. Rioja-Paradela, A. Carrillo-Reyes, 
and E. Bastiaans. 2015. Variation in the thermal ecology of an endemic iguana from Mexico reduces its vulnerability to global warming. Journal of Thermal Biology 48:56-64.

van Dijk, P.P., L. Canseco-Marquez, and A. Muñoz. 2007. Rhinoclemmys rubida. The IUCN Red List of Threatened Species 2007:e.T19508A97376969. DOI: http://dx.doi.org/10.2305/IUCN.UK. 2007.RLTS.T19508A8941198.en.

Vogt, R.C., S.G. Platt, and T.R. Rainwater. 2009. Rhinoclemmys areolata (Duméril and Bibron 1851), furrowed wood turtle, black-bellied turtle, mojena. Chelonian Research Monographs 5:22-27.

Whittingham, M., P. Stephens, R. Bradbury, and R. Freckleton. 2006. Why do we still use stepwise modelling in ecology and behaviour? Journal of Animal Ecology 75:1182-1189.

Wilson, D.S. 1994. Tracking small animals with thread bobbins. Herpetological Review 25:13-14.

Worton, B.J. 1989. Kernel methods for estimating the utilization distribution in home-range studies. Ecology 70:164-168.
Xia, J.Y., L. Chen, Y.Q. Wang, and B.H. Chen. 1983. Comparative studies and observations on habits of turtles in southern Anhui. Sichuan Journal of Zoology 2:30-34.

Xiao, F., J. Wang, H. Shi, Z. Long, L. Lin and W. Wang. 2017. Ecomorphological correlates of microhabitat selection in two sympatric Asian box turtle species (Geoemydidae: Cuora). Canadian Journal of Zoology 95:753-758.

Zai-Zhong, L., W. Ji-Chao, X. Fanrong, and S. Hai-Tao. 2016. Diurnal activity rhythms and time budgets of Cuora mouhotii and C. galbinifrons. Chinese Journal of Ecology 35:2164-2169.

Accepted on 4 April 2018 Associate Editor: Chris Gienger 
APPENDIX I.-Summary data for 19 thread-spooled or radiotracked Rhinoclemmys rubida perixantha ID $=$ turtle number, CL $=$ straight-line carapace length $(\mathrm{mm})$, monitoring period $=$ first and last date that turtles were monitored, $\mathrm{O}=$ total number of times the individual was observed (individuals did not always move between observations), $\mathrm{R}=$ total number of times the subject moved, SLD = mean ( $\pm 95 \%$ confidence interval $)$ straight-line distance moved between locations. Home range estimators: $\mathrm{MCP}=$ minimum convex polygon, $\mathrm{K}_{95 \%}=95 \%$ kernel density, and $\mathrm{BB}_{95 \%}=95 \%$ Brownian bridge. Home ranges were calculated for only those subjects having $>30$ relocations.

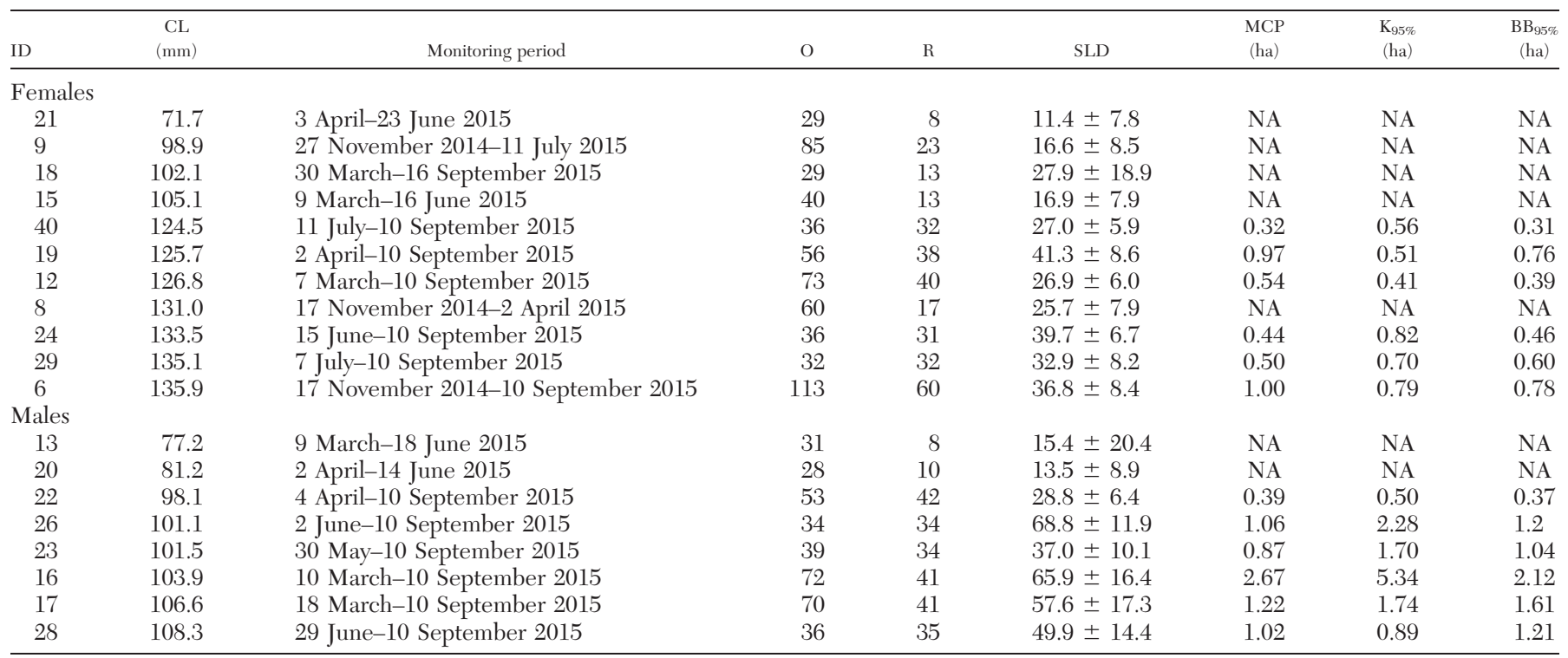

APPENDix II.-Summary of straight-line distances (m) that Rhinoclemmys rubida perixantha moved between season, sex, and sex-season. These data are from 486 different observations, and calculated in $\mathrm{R}$ with the ltraj function from the adehabitatLT package.

\begin{tabular}{lrr}
\hline & $n$ & Distance $( \pm 95 \% \mathrm{CI})$ \\
\hline Dry season & 80 & $14.4 \pm 2.80$ \\
Wet season & 406 & $42.80 \pm 3.11$ \\
Male & 198 & $47.7 \pm 5.31$ \\
Female & 288 & $31.6 \pm 2.77$ \\
Dry season-male & 22 & $13.2 \pm 5.69$ \\
Dry season-female & 58 & $14.9 \pm 3.31$ \\
Wet season-male & 176 & $52.0 \pm 5.62$ \\
Wet season-female & 230 & $35.8 \pm 3.15$ \\
\hline
\end{tabular}

